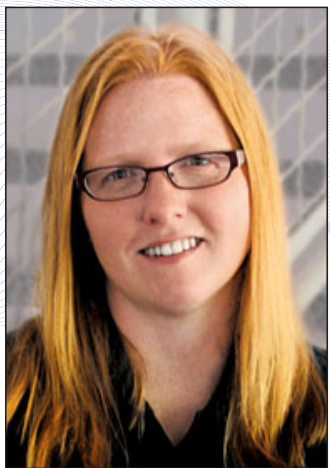

Kristi S. Anseth

2016 MRS President

\title{
A new chapter for MRS Meetings
}

As we turn our calendars to the new year, we also turn the page to an exciting new chapter for MRS Meetings. The MRS Spring Meeting began in Albuquerque, N.M., in 1984, then, in addition to Reno, Nev., moved throughout California-Palo Alto, Anaheim, and San Diego-before landing in San Francisco in 1990. All along, the MRS Spring Meeting prospered, growing from four symposia in Albuquerque, to 51 symposia last year. The scope of the Spring Meeting expanded as well - from technical symposia with the usual poster sessions and tutorials, to a growing array of attendee offerings in the areas of professional development and career opportunities, special forums, government agency sessions, public outreach and advocacy activities, additional award talks, industry programming, and more.

This successful evolution, however, came with consequences. The Spring Meeting literally outgrew the convention center in San Francisco, and a three-venue arrangement was not conducive to the networking and interdisciplinary nature that lies at the heart of the MRS Meeting. We had a great "extended stay" in San Francisco, but it was time for a change.

Convening the 2016 MRS Spring Meeting in Phoenix, Ariz., brings us full circle - with all activities once again within a single venue and with flexibility to accommodate a record 63 symposia, ensuring a blend of established, emerging, and new topics. Named one of the top 10 convention center facilities in the United States, the state-of-the-art Phoenix Convention Center also fulfills the demand for broader impact and expanded Innovation ConneXions programming, as well as advanced technology to meet our attendees' needs for increased bandwidth.

So what's new and exciting for the Spring Meeting?

- Furthering our industrial engagement initiative, an expanded Innovation in Materials Science (iMatSci) program will include an Angel Investing Panel, as well as an Entrepreneurship Skills Workshop and tour of Arizona State University's (ASU) SkySong - a dynamic center for innovation, technology, and economic expansion. The 10th Technology Innovation Forum (TIF), addressing National Laboratories and Technology Innovation, will begin with a keynote address by Dr. Steven Chu, US Secretary of Energy from 2009 to 2013, and co-winner of the 1997 Nobel Prize in Physics.

- Focus on Sustainability also takes center stage with a symposium and tutorial on Materials for Sustainable Development, including a half day devoted to Sustainability and Industry; a professional development workshop on How to Incorporate Sustainability Principles into Materials Research; a University Chapter Poster Exhibition on Sustainability in My 
Community; and, in partnership with the ASU Walton Sustainability Solutions Initiatives program Sustainability in Science Museums, hands-on activities and resources to help museums and educators engage the public in sustainability science and practice.

- Currently in development is a student-run energy symposium, Harnessing the Power of Solar. A collaboration between MRS University Chapters from ASU and the University of South Dakota, the focus will be on reducing power dependence on fossil fuels.

- On the heels of an informative and interactive MRS Bulletin Special Issue Session at the 2015 MRS Fall Meeting on Materials \& Engineering: Propelling Innovation, the Bulletin team is planning a follow-up session for the Spring Meeting.

- In addition to the Spring Meeting Career Fair, which will feature on-site interviews, resume critiques, mock interviews, career coaching, and social media photos, Career Central is also busy planning a wide array of diverse and valuable professional development sessions and workshops. In particular, MRS plans to partner with the ASU Walter Cronkite School of Journalism and Mass Communication to develop a session on Using Social Media to Improve Science Communication and Collaboration. Additional career workshop topics under consideration include Networking at a conference, even if you're not there! and Successfully navigating the international job search.

- Popnology. If you haven't already heard the term, you will when you get to Phoenix. The Arizona Science Center will host the world premiere of Popnology — an exhibition that highlights how technology has been influenced by movies, books, television, and art. The exhibition will be open during the MRS Spring Meeting week, and MRS is negotiating with the Science Center for a limited number of discounted passes for our attendees.

- And last, but certainly not least, you won't want to miss The Hub events. This "hub of activity" is your place to connect-with Exhibitors, colleagues, Public Outreach, Materials Voice, the MRS and Cambridge University Press publications team, the Career Fair, and the Cyber Café/Help Desk. In addition, The Hub Stages will feature award talks, special presentations, and Symposium X—Materials in Musical Instruments, which will be followed by musical entertainment and a reception.

This is just a sampling of the interesting and informative events being planned by our 2016 MRS Spring Meeting Chairs, volunteers, and headquarters staff.

I know that you will enjoy the new home of our MRS Spring Meeting, and I look forward to seeing you in Phoenix!

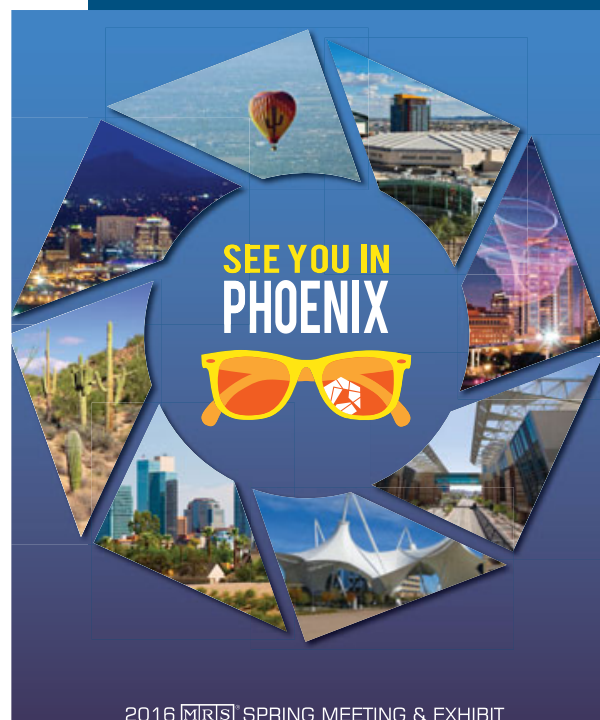

2016 MRS SPRING MEETING \& EXHIBIT

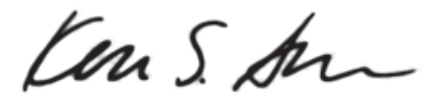

Kristi S. Anseth 2016 MRS President 